\title{
Form and intertextuality in movie music videos
}

\author{
Brent Ferguson, Ph.D. ${ }^{1 \dagger}$ \\ ${ }^{1}$ Washburn University, Topeka, Kansas, United States \\ $\dagger$ Corresponding author: brent.ferguson@washsburn.edu \\ Published 16 December 2021; https://doi.org/10.18061/FDMC.2021.0040 \\ Author video presentation and/or other conference material: https://doi.org/10.17605/OSF.IO/8DHBZ
}

\begin{abstract}
This paper addresses a phenomenon I call the Movie Music Video (MMV henceforth). A MMV is a music video for a soundtrack song displaying intertextual relationships with its corresponding film, such as intercutting clips of the film in the mise en scene, using costumes from the film, or telling a film's narrative through lyrics. My primary goal in this paper is to calculate the frequency of certain intertextual relationships, or types between the music video and the film. For the secondary goal, I demonstrate a methodology for the analysis of this novel medium, focusing particularly on form and intertextuality. To do this, I create an analytical style borrowing from multi-domain form graphs to display song form aligned with visual information and types of intertextuality.

Most MMVs contain four independent texts in its mise en scene: its video diegesis, the corresponding film, its song and performing artist. Just as Lafrance and Burns (2017) emphasizes that the analysis of any music video should include visual, lyrical, and musical domains, my examples can be broken down into three categories based on whether the MMV references the corresponding film through visual, lyrical, or aural domains. My graphs highlight film references in the music video. Such references tighten intertextual bonds between multimedia, serving as tethers between texts. Using form graphs of MMVs, my paper demonstrates the rich interplay between texts executed through music form.
\end{abstract}

KEYWORDS: corpus study, music video, film, form, intertextuality

\section{Introduction}

Movie music videos (MMVs henceforth) feature scenes of the artist performing their song intercut with clips from the film. In MMVs, elements of the song or video reference the film through lyrical content, musical quotes, and visual stimuli. Presentations of different intertexts in MMVs are often associated with sections of the song form. The types of visual intertextuality this article covers include the use of intercuts, superimpositions (typically of intercuts), as well as film settings, costumes, actions, and celebrities from the film. Lyrical intertextuality includes the employment of a film's title as the song's title, alluding to the film's themes or actions in the lyrics, and the lyrics telling the film's narrative. Types of aural intertextuality includes the quotation of theme songs from a another medium (for films based off other multimedia), the film composer as a producer of the song recycling content from the film's musical score, the use of dialogue and sound effects from the film, and covering or sampling other music.

The goal of this research is to document the three types of intertexts in a corpus-driven study of 174 MMVs. I adapt a type of multi-domain form graph (see Burns, 2017; Osborn, 2020) to exhibit how song form organizes these intertexts within the MMV. This research builds on, and contributes to, musicological intertextuality by adapting pre-existing models to create a new method of analysis designed specifically to highlight textual relationships in MMVs. As a multimedia chimera, MMVs often provide intertextual links between the song, multiple visual worlds, celebrities, and sometimes brands. These various texts interact in counterpoint exclusive to the medium. With the recent interest in music video scholarship and intertextuality of popular music-evidenced by the publication of The Bloomsbury Handbook of Popular Music Video Analysis (2019) and The Pop Palimpsest (2018), respectively - this work adds to these growing canons including research from film and media studies, as well as recent literary scholars.

\section{Method}

Selecting videos for this corpus was built from three methods: the author's personal memory, the memory of their acquaintances, and searching the internet. YouTube yielded all but two of the additional examples. For every MMV found, details were sought related to it including: its title, artist, film title, song's release date, video's release date, film's release date, the MMV's director, any featured artists, and additional information through interviews, analyses, and other metatexts. I stopped collecting MMVs for the corpus on November 11, 2019. Within this corpus, which includes MMVs produced between 1980 and 2019, the span of 2000- 
2013 is represented with the fewest videos per year. This drought could relate to the decline of music television followed by music video's recent resurgence on the internet.

After the corpus was established, a spreadsheet was created with all the information and blank columns with the following headings for visual film intertextuality, lyrical intertextuality with narrative, and aural intertextuality, along with their subtypes. Each of the 174 MMVs were viewed at least twice. The first viewing consisted of concentrating on all aspects of the video without taking notes. My second viewing involved putting a " 1 " in the respective box of the categories present in the MMV. Additional viewings were warranted depending on the quantity of intertextuality in the MMV or the depth of analysis provided.

\section{Results}

Table 1 displays the total amounts of intertextual types between visual, lyrical, and aural. Only two MMVs did not exhibit visual intertextuality. Almost half of the MMVs possessed aural intertextuality with the film or other musical sources. This does not account for the MMV song's usage in the corresponding film's soundtrack. Under a third of the MMVs in the study utilized lyrical intertextuality.

Table 1: MMV Intertextuality Types and Results

$\begin{array}{ll}\text { Intertextuality Type } & \text { Total (Percentage) } \\ \text { Visual } & 172(98.85 \%) \\ \text { Lyrical } & 53(30.46 \%) \\ \text { Aural } & 83(47.7 \%)\end{array}$

Table 2: MMV Intertextuality Subtypes and Results

\begin{tabular}{|c|l|l|l|}
\hline Intertext Type & \multicolumn{1}{|c|}{ Subtype } & Total & Percent \\
\hline Visual & Intercuts & 141 & $80.6 \%$ \\
& Superimpositions & 56 & $32 \%$ \\
& Setting & 94 & $53.7 \%$ \\
& Costume & 43 & $24.6 \%$ \\
& Action & 46 & $26.3 \%$ \\
& Brands & 37 & $21.1 \%$ \\
& Celebrities & 50 & $28.6 \%$ \\
\hline Lyrical & Title Songs & 24 & $13.7 \%$ \\
& Allusions & 10 & $5.7 \%$ \\
& Narratives & 20 & $11.4 \%$ \\
\hline \multirow{2}{*}{ Aural } & Theme Quote & 7 & $4 \%$ \\
& Score Quote & 24 & $13.7 \%$ \\
& Dialogue/SFX Quote & 39 & $22.3 \%$ \\
& Other Music Quote & 26 & $14.9 \%$ \\
\hline
\end{tabular}

Specific subtypes of intertextuality and their results are shown in Table 2. Intercuts of the cotextual film are the most common intertextual binds in MMVs with just over $80 \%$. Utilizing film settings in MMVs occur in more than half of MMVs. While only occurring in roughly $13 \%$ of MMVs, employing the film's title as the song's title (and usually a line in the chorus) is the prevailing lyrical intertextuality, and just under that are songs that tell the film's narrative through its lyrics. Most aural intertextualities are samples of the film's dialogue and sound effects to accompany intercuts during the MMV; these do not occur on the soundtrack album version of the songs.

\section{Discussion}

Visual intertextuality serves as the vital narrative link between MMVs and film, because film is most prominently visual multimedia. One of Claudia Gorbman's main arguments in the groundbreaking Unheard Melodies (1987) is that music is secondary to the visual domain in the classical Hollywood film. We can see intertextual tethers between the song and film because of the MMV. Our eyes make an immediate connection between intercuts (or superimpositions) and the MMV diegesis. Citing costumes, settings, and characters in the video diegesis elicits a synergetic narrative world within the MMV. The mise en scene showing the artist performing actions from the film casts the artist as an actor in the film's narrative world without actually being cast in the film. Thus, MMVs become part of the film's lore - the world of the narrative not shown through the film.

Lyrical intertextuality combines the verbal and aural realms; a lyricist writes the lyrics and a singer performs them. Linking the film to the song through lyrical allusions and narratives provide similar intertextual tethers to the film. Text painting, or allusion, in MMVs through aligning certain visuals with lyrics further spins the intertextual web between multimedia. Presenting lyrical narratives and complex visual intertextualities secures the MMV as a convergent advertisement for the film and song, respectively.

Unlike lyrical or visual intertextuality, aural intertextuality does not always depend on references to the film. A MMV can utilize other texts related to the film, such as films based on other media, in the case of a producer sampling or covering older music. Importing dialogue and sound effects from the film push the MMV more towards "movie trailer" territory, but it also increases advertising quality of the MMV. Referencing 
outside musical works pushes the MMV's marketing value to include the previous media as well.

While I did not document the amount of times song form organized intertextualities, this article includes two form graphs that display how this works in MMVs. Table 3 displays a form graph for the MMV for Will Smith's Wild Wild West from the film of the same title. The symbol $>$ notates a change of setting, and this happens during each Chorus in Wild Wild West. Each verse and chorus pairing organizes both visual setting and lyrical narratives. The three settings are displayed in Figure 1. The first pairing displays a burning town with the exposition of the story and a description of its characters. During the second pairing, the visual setting shifts to the insides of a mechanical spider along with the lyrics describing the main conflict in the film and its antagonist. The final pairing (Verse 3 and Chorus 4), with the non-musical episode beforehand utilizes a mansion setting with lyrical allusions to the filmic action.

Table 4 shows a similar alignment of settings and song form in Puff Daddy's Come With Me, and it also displays the sections sampled from the Led Zeppelin song Kashmir (sections shown in Figure 1). Like Wild Wild West, Come With Me features rapid changes of scenery until halfway through the song. At this point, the camera centers on Puff Daddy in Times Square with an orchestra behind him. Tables 3 and 4 display a sample of multi-domain analyses.

\section{Conclusion}

Visual intertextuality prevails as the most common referential device in MMVs due to its format as visual medium. Intercuts being the preferred visual intertextuality is attributed to the affection for this format in its early days. MMVs are a type of advertisement for a film (see Gray, 2010; Hayward \& Fitzgerald, 2016; Summers, 2020), and intercutting parts of the film in an MMV mise en scene makes the advertising intent clear-it takes on the persona of a trailer while being simultaneously a music video. Employing the same titles between film and MMV refers to a practice in Hollywood that predates MTV: the commission of songs for film and television. Unique to MMV, apart from its corresponding soundtrack song, is its ability to capture film sound and dialogue occurring with intercuts. This pushes the MMV further into the territory of a trailer advertisement. Other MMVs play on the consumer's nostalgia by sampling popular songs in recent memory. In all, MMVs are effective musical

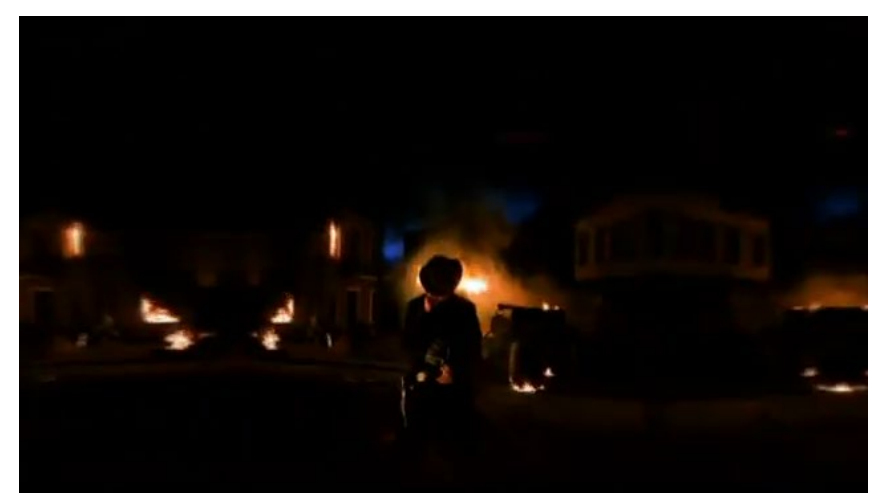

Burning Town

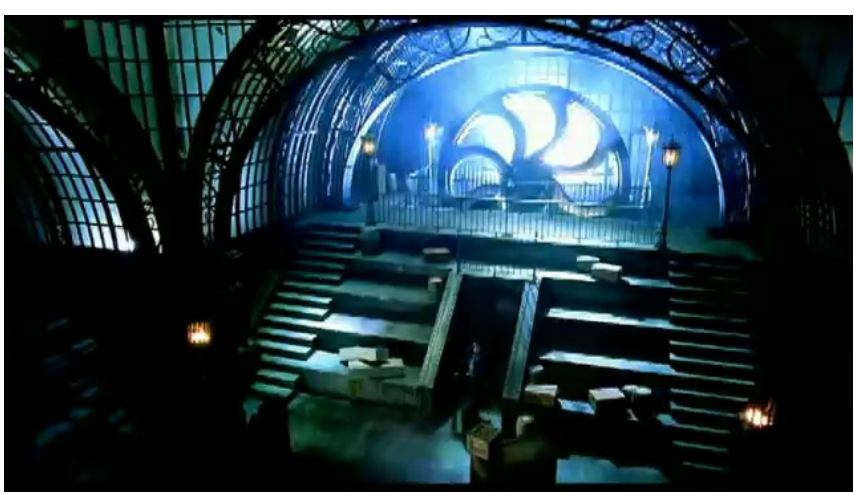

Mechanical Spider (Inside)

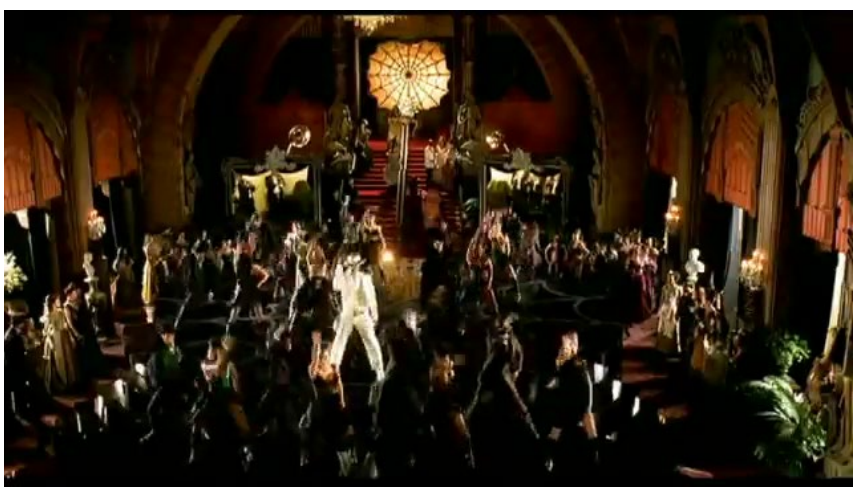

Mansion

Figure 1 : Settings in Wild Wild West MMV

advertisements that not only market the film with trailer like references, it markets the artist and their song. Due to this, MMVs might be more effective advertisements than movie trailers. This is apparent with a rise in the use of MMVs in the last five years alongside the use of samples or covers of popular music in blockbuster trailers. I predict that MMVs will continue to be a preferred advertising method for films and artists, and studios will continue to find more ways to expose audiences to these marketing entities. 
Table 3: Wild Wild West MMV Form Graph

\begin{tabular}{|c|c|c|}
\hline $\begin{array}{l}\text { Song } \\
\text { Section }\end{array}$ & Mise en scene & Intertextuality \\
\hline Introduction & $\begin{array}{l}\text { Desert }>\text { Burning } \\
\text { Town }\end{array}$ & $\mathrm{N} / \mathrm{A}$ \\
\hline Verse 1 & Burning Town & $\begin{array}{l}\text { Lyrical Narrative - } \\
\text { Character description } \\
\text { of Jim West } \\
\text { Intercuts }\end{array}$ \\
\hline Chorus 1 & $\begin{array}{l}\text { Burning Town > } \\
\text { Mechanical } \\
\text { Spider (inside) }\end{array}$ & Title Lyric \\
\hline Verse 2 & $\begin{array}{l}\text { Mechanical } \\
\text { Spider (inside) }\end{array}$ & $\begin{array}{l}\text { Lyrical Narrative - } \\
\text { Character description } \\
\text { of Arliss Loveless } \\
\text { and conflict } \\
\text { Superimpositions }\end{array}$ \\
\hline Chorus 2 & $\begin{array}{l}\text { Mechanical } \\
\text { Spider (inside) > } \\
\text { Mansion }\end{array}$ & $\begin{array}{l}\text { Title Lyric } \\
\text { Superimpositions }\end{array}$ \\
\hline $\begin{array}{l}\text { Dramatic } \\
\text { Break }\end{array}$ & Mansion & $\begin{array}{l}\text { Other celebrities } \\
\text { Sampled Artist } \\
\text { Character - Arliss } \\
\text { Loveless } \\
\text { Aural - Film score }\end{array}$ \\
\hline Chorus 3 & & $\begin{array}{l}\text { Title Lyric } \\
\text { Sampled Artist }\end{array}$ \\
\hline Interlude & & $\mathrm{N} / \mathrm{A}$ \\
\hline Verse 3 & & Lyrical Allusions \\
\hline $\begin{array}{l}\text { Chorus } 4 \\
\text { Outro } \\
\end{array}$ & & Title Lyric \\
\hline
\end{tabular}
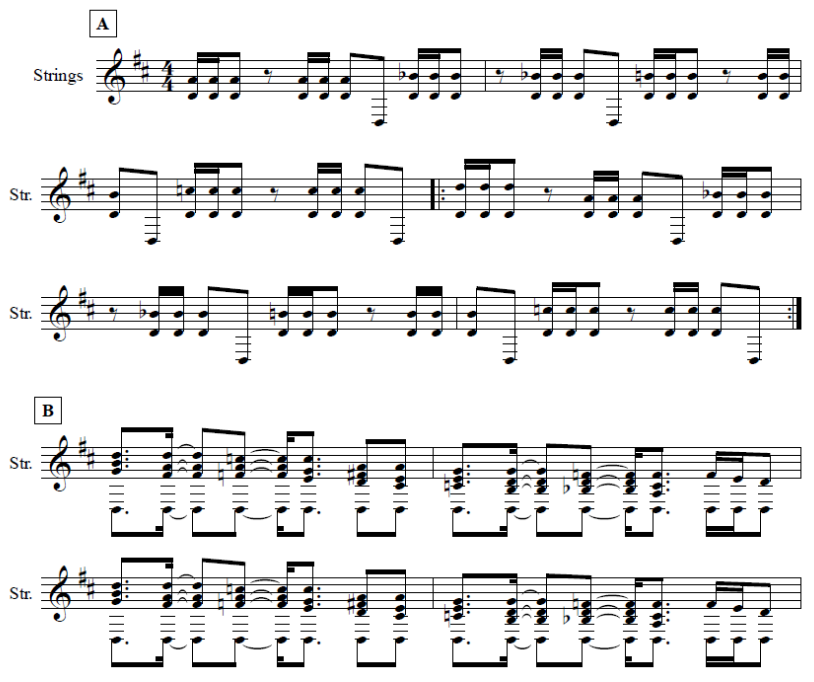

C

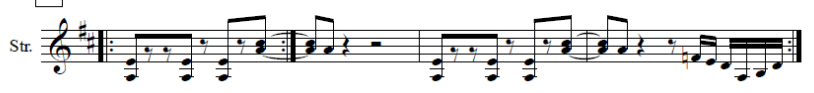

Figure 2 : Sections of Kashmir in Come With Me

Table 4: Come With Me MMV Form Graph

\begin{tabular}{|c|c|c|}
\hline Song Section & Sampled Section & $\begin{array}{l}\text { Video Diegesis } \\
\text { Setting }\end{array}$ \\
\hline $\begin{array}{l}\text { Dramatic } \\
\text { Introduction }\end{array}$ & No Music & \multirow[t]{3}{*}{ Apartment } \\
\hline $\begin{array}{l}\text { Musical } \\
\text { Introduction }\end{array}$ & \multirow[t]{2}{*}{ A } & \\
\hline Verse 1 & & \\
\hline Chorus 1 & $\mathrm{~B}$ & Apartment $>$ Elevator \\
\hline Verse 2 & $\mathrm{~A}$ & Elevator \\
\hline Chorus 2 & $\mathrm{~B}$ & Elevator $>$ Sky \\
\hline Bridge & Original & Sky \\
\hline Interlude 1 & \multirow[t]{2}{*}{ A } & \multirow{8}{*}{$\begin{array}{l}\text { Stage (in Times } \\
\text { Square) }\end{array}$} \\
\hline Verse 3 & & \\
\hline Chorus 3 & $\mathrm{~B}$ & \\
\hline Interlude 2 & $\mathrm{C}$ & \\
\hline Verse 4 & $\mathrm{~A}$ & \\
\hline Chorus 4 & $\mathrm{~B}$ & \\
\hline Verse 5 & \multirow[t]{2}{*}{$\mathrm{A}$} & \\
\hline Outro & & \\
\hline
\end{tabular}

\section{Acknowledgements}

I want to thank all of the people who helped shape and edit my research, and this includes T.J. Laws-Nicola, Matthew Ferrandino, and Brad Osborn. 


\section{References}

Burns, L. (2017). Multimodal analysis of popular music video: genre, discourse, and narrative in Steven Wilson's "Drive Home." In C.X. Rodriguez (Ed.) Coming of Age: Teaching and Learning Popular Music in Academia. Michigan Publishing Services.

Burns, L. \& Hawkins, S. (Eds.). (2019). The Bloomsbury Handbook of Popular Music Video Analysis. Bloomsbury Academic. https://doi.org/10.5040/9781501342363

Burns, L. \& Lacasse, S. (2018). The Pop Palimpsest: The Intertextuality in Recorded Popular Music. University of Michigan Press. https://doi.org/10.3998/mpub.9755813

Fitzgerald, J. \& Hayward, P. (2016). Paranormal product: the music and promotion of Ghostbusters. In M. Evans \& P. Hayward (Eds.) Sounding Funny: Sound and Comedy Cinema. Equinox Publishing.

Genette, G. (1987). Palimpsestes: La littérature au second degré. Seuil.

Gorbman, C. (1987). Unheard Melodies. Indiana University Press.

Gray, J. (2010). Show Sold Separately: Promos, Spoilers, and Other Media Paratexts. University of New York Press.

Hatten, R. (1985). The place of intertextuality in music studies. American Journal of Semiotics, 3(4), 69-82.

Klein, M. (2005). Intertextuality in Western Art Music. Indiana University Press.

Kristeva, J. (1969). The Kristeva Reader, ed. Toril Moi. Columbia University Press.

Lafrance, M. \& Burns, L. (2017). Finding love in hopeless places: complex relationality and impossible heterosexuality in popular music videos by P!nk and Rihanna. Music Theory Online 23(2). https://doi.org/10.30535/mto.23.2.5

Osborn, B. (2020). Risers, drops and a fourteen-foot cube: a transmedia analysis of Emil Nava, Calvin Harris and Rihanna's This Is What You Came For. In C. Vernallis, H. Rogers, and L. Perrott (Eds.) Transmedia Directors: Artistry, Industry and New Audiovisual Aesthetics. Bloomsbury Academic. https://doi.org/10.5040/9781501339295.0020

Summers, T. (2018). From "Sabotage" to "Sledgehammer": trailers, songs, and the musical marketing of Star Trek Beyond (2016)." Music and the Moving Image 11(1), 4065. https://doi.org/10.5406/musimoviimag.11.1.0040

Vernallis, C. (2004). Experiencing Music Video: Aesthetics and Cultural Context. Columbia University Press. 